\title{
Surface charge of polymer coated SPIONs influences the serum protein adsorption, colloidal stability and subsequent cell interaction in vitro†
}

\begin{abstract}
Vera Hirsch, ${ }^{\text {ab }}$ Calum Kinnear, ${ }^{a}$ Marc Moniatte, ${ }^{d}$ Barbara Rothen-Rutishauser, ${ }^{\text {ac }}$ Martin J. D. Clift ${ }^{a}$ and Alke Fink*ab

It is known that the nanoparticle-cell interaction strongly depends on the physicochemical properties of the investigated particles. In addition, medium density and viscosity influence the colloidal behaviour of nanoparticles. Here, we show how nanoparticle-protein interactions are related to the particular physicochemical characteristics of the particles, such as their colloidal stability, and how this significantly influences the subsequent nanoparticle-cell interaction in vitro. Therefore, different surface charged superparamagnetic iron oxide nanoparticles were synthesized and characterized. Similar adsorbed protein profiles were identified following incubation in supplemented cell culture media, although cellular uptake varied significantly between the different particles. However, positively charged nanoparticles displayed a significantly lower colloidal stability than neutral and negatively charged particles while showing higher non-sedimentation driven cell-internalization in vitro without any significant cytotoxic effects. The results of this study strongly indicate therefore that an understanding of the aggregation state of NPs in biological fluids is crucial in regards to their biological interaction(s).
\end{abstract}

\section{Introduction}

With the ever increasing manipulation of objects at the nanoscale, an abundance of possibilities are being realized for both medical and consumer applications. ${ }^{\mathbf{1}}$ In recent years, numerous studies have focused on the interaction of nanoparticles (NPs) with living matter for both their application in medicine (nanomedicine) ${ }^{2}$ as well as their relative health and environmental risk assessment (nanotoxicology)., ${ }^{3,4}$ This issue is of tremendous importance, since there is a growing consensus that an understanding of these fields has not kept pace with the explosive development of nano-based materials in the past decade. ${ }^{5}$

The cellular interaction of NPs is known to be strongly dependent on their physicochemical properties (e.g. material,

${ }^{a}$ Adolphe Merkle Institute, University of Fribourg, Route de l'Ancienne Papeterie, P.O. Box 209, 1723 Marly 1, Switzerland. E-mail: alke.fink@unifr.ch; Fax: +41 26300 9624; Tel: +41263009501

${ }^{b}$ Department of Chemistry, University of Fribourg, Chemin du Museé 9, 1700 Fribourg, Switzerland

${ }^{c}$ Respiratory Medicine, Bern University Hospital, Inselspital, Freiburgstrasse, 3010 Bern, Switzerland

${ }^{d}$ Proteomics Core Facility, École Polytechnique Fédérale de Lausanne, Station 15, 1015 Lausanne, Switzerland

$†$ Electronic supplementary information (ESI) available: Sodium dodecyl sulphate-polyacrylamide gel electrophoresis (SDS-PAGE) gels, cytotoxicity, concentration measurements by Ultraviolet/Visible Spectroscopy (UV/Vis) and calculation of sedimentation parameters. size, shape and surface charge). ${ }^{6-9}$ In particular, the surface charge of NPs is known to be one of the essential factors that directly relates to their cellular uptake. ${ }^{10,11}$ Prior to contact with cellular systems, and irrespective of their exposure route to the human body, NPs interact with complex biological environments that are fluid-based and consist of a range of biomolecules such as proteins and lipids in addition to electrolytes. ${ }^{12,13}$ Therefore, NPs should be classified according to the manner in which they interact with biological fluids, before assessing any cellular interaction either in vivo or in vitro.

When suspended in biological fluids, the physicochemical properties of NPs can undergo rapid changes leading to the formation of new entities. ${ }^{\mathbf{1 4 , 1 5}}$ Recently, the effects of size, shape and surface characteristics of NPs in regards to their specific protein interaction have received increasing interest, ${ }^{16-19}$ especially within the field of nanotoxicology. ${ }^{20}$ Although it has been reported that the NP composition clearly influences protein binding, the surface properties, namely hydrophobicity and charge, are likely to be most important. ${ }^{21}$ Furthermore surface charge of NPs plays a key role in terms of their colloidal stability as it directly impacts on the electrostatic repulsion of NPs when in suspension. ${ }^{22}$

As for example, larger gold NPs suspended within cell culture media, or possible aggregates, can display an increased sedimentation rate. ${ }^{23}$ This increased sedimentation of NPs in cell cultures can lead to a locally higher concentration on the cell surface, and subsequently elicit a higher, and misrepresentative, cellular uptake. ${ }^{24,25}$ The sedimentation of NPs is a function 
of their physical properties (e.g. material density) and local environment (e.g. medium viscosity). How these factors influence the NP-cell interaction, as of today, is not fully understood.

An example of NPs whose potential use and application in biomedicine have drastically increased in recent years are superparamagnetic iron oxide nanoparticles (SPIONs), ${ }^{26-29}$ as they represent advantageous tools in the field of magnetic separation (e.g. rapid DNA sequencing), ${ }^{29}$ in vivo medical imaging (as MRI contrast enhancers), ${ }^{30-33}$ drug delivery, ${ }^{34,35}$ tissue repair ${ }^{36}$ and hyperthermia ${ }^{37}$ as summarized by Veiseh and colleagues. ${ }^{38}$ In order to promote these compounds towards clinical development, an improved understanding of how such particles interact with living matter when they are injected into the blood circulation is of utmost importance. The aim of the present study was to investigate how the surface charge of polyvinyl alcohol (PVA) coated SPIONs determines their protein adsorption patterns in fetal bovine serum, how such NP-protein interactions relate to the physicochemical characteristics of the NPs (e.g. colloidal stability) and how this subsequently influences the NP-cell interaction in vitro.

\section{Results and discussion}

\section{Particle characterization}

SPIONs were synthesized as described previously by alkaline coprecipitation of ferric and ferrous chlorides in water ${ }^{39}$ and were subsequently coated with polyvinyl alcohol (PVA), vinylalcoholvinylamine co-polymer or carboxylated PVA (i.e. PVA with randomly distributed carboxylic acid groups) in order to obtain different charged surfaces. Hereafter, the product of these reactions will be referred to as PVA-SPIONs (i.e. neutral PVA coated SPIONs), p-PVA-SPIONs (i.e. positively charged aminated PVA SPIONs), and n-PVA-SPIONs (i.e. negatively charged carboxylated PVA SPIONs).

The uncoated SPIONs were characterized thoroughly by X-ray diffraction (XRD), surface area measurements (Brunner, Emmet and Teller (BET) method), and magnetic measurements as previously reported..$^{39}$ Polymer coated SPIONs showed a mean diameter $(d 50)$ of $34.9 \pm 7.2 \mathrm{~nm}$ as obtained by dynamic light scattering (DLS) and a positive zeta potential of $-5.9 \pm 0.9 \mathrm{mV}$, $29.4 \pm 1.3 \mathrm{mV}$ and $1.5 \pm 2.3 \mathrm{mV}(\mathrm{pH}=7)$ for n-PVA-SPIONs, p-PVA-SPIONs and PVA-SPIONs, respectively. For the coherence of the study and in order to only vary the zeta potential of the synthesized polymer coated SPIONs we kept size, surface grafting density, and composition constant. The characterization of the NPs clearly shows that only the zeta potential varies between each NP type, whereas the particle sizes remain comparable (Table 1). A transmission electron micrograph is shown as an example for p-PVA-SPIONs (Fig. 1).

\section{NP-protein interactions}

To determine the protein adsorption patterns of the different surface charged PVA-SPIONs, a magnetic fixed bed reactor was utilized to immobilize the NP-protein complexes and recover the adsorbed serum proteins in a closed system. ${ }^{44}$ Whilst there are other methods available to recover adsorbed biomolecules,
Table 1 Mean particle size and zeta potential $(\mathrm{pH}=7)$ of polymer coated SPIONs

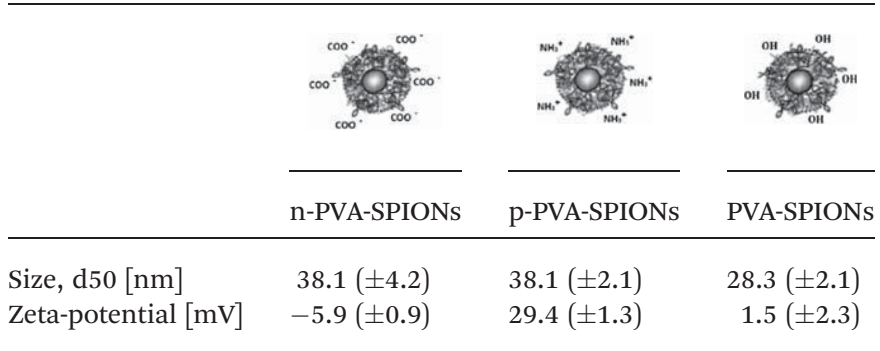

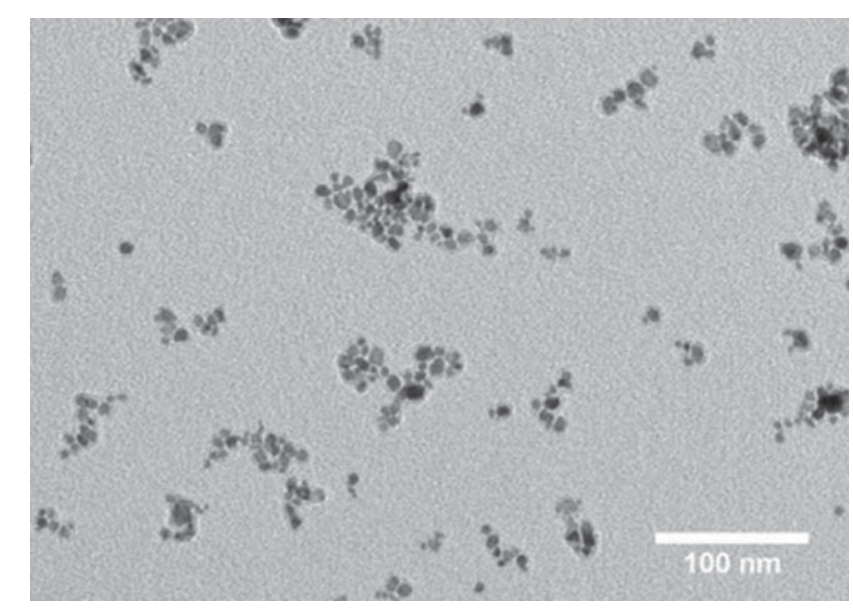

Fig. 1 Transmission electron microscopy image of p-PVA-SPIONs.

such as centrifugation, ${ }^{48,5}$ gel filtration or membrane-based microfiltration, ${ }^{49}$ the scientific protocol used within the present study is pertinent and specific to the NPs employed, as SPIONs offer the advantage of protein elution by magnetic separation. Compared to these alternative methods, the adsorption patterns obtained using the magnetic fixed bed reactor are qualitatively comparable, but with a higher quantitative recovery of proteins and particles.$^{50}$ Furthermore, the method is considered significantly less time consuming and of an inherently greater reproducibility. ${ }^{44}$

During the exposure of NPs to biological fluids, the composition of the adsorbed protein coating undergoes dynamic changes. Therefore it is important not only to determine which proteins are adsorbed onto the surface of the NPs, but also to understand the binding kinetics and affinities. ${ }^{21}$

Investigation of the PVA-SPION-protein interaction, initially observed via sodium dodecyl sulphate-polyacrylamide gel electrophoresis (SDS-PAGE), showed an intensity difference within the SDS gel bands after $1 \mathrm{~h}$ of incubation in serum (fetal bovine serum (FBS)) for both PVA-SPIONs and p-PVA-SPIONs, as these NPs adsorbed a higher quantity of proteins compared to n-PVASPIONs (elution fraction E2, eluted with a $50 \mathrm{mM}$ aqueous solution of $\mathrm{KCl}$ ). In contrast, it was observed that after $16 \mathrm{~h}$ of incubation n-PVA-SPIONs adsorb an increased amount of serum proteins compared to the other two NP types. In addition, it is essential to note that after $16 \mathrm{~h}$ the binding strength of serum proteins to the surface of n-PVA-SPIONs is increased relative to the other particles incubation, as bands are still 
visible after extensive elution (elution fraction E6, eluted with a $100 \mathrm{mM}$ aqueous solution of $\mathrm{KCl}$ ) (Fig. S1 and S2, ESI $\dagger$ ).

To further identify the specific adsorbed proteins, selected bands of the E2 and E6 fractions were excised from the SDS gels followed by in-gel trypsin digestion and identification by positive electrospray ionization liquid chromatography with tandem mass spectrometry (ESI + LC-MS/MS). Table 2 summarizes the proteins that were identified on all investigated PVA-SPIONS, irrespective of the incubation time or surface charge. Table 3 shows the variations between the three different surface charges investigated. Complement (C) 3 was only identified on the surface of p-PVA-SPIONs after $16 \mathrm{~h}$ of incubation in FBS. Hemopexin adsorbed on n- and p-PVA-SPIONs after $16 \mathrm{~h}$, whereas the protein was not detected after $1 \mathrm{~h}$ of incubation. Angiotensinogen and antithrombin III were detected after only $1 \mathrm{~h}$ of incubation on p-PVA-SPIONs and PVA-SPIONs and were only detected on n-PVA-SPIONs after $16 \mathrm{~h}$. Similar behavior was also observed for apolipoprotein A1, which was detected only on PVA-SPIONs after $1 \mathrm{~h}$ (Table 2).

Serum albumin, alpha-2-HS-glycoprotein, alpha-1-anitproteinsase and alpha-fetoprotein were found to adsorb strongly on the n-PVA-SPIONs after $16 \mathrm{~h}$ of incubation, as they were still detectable after extensive elution in elution fraction E6.

The high affinity of abundant serum proteins towards all investigated NPs inhibited the detection of less abundant serum proteins by mass spectrometry and only allowed minor differences in the adsorption patterns to be identified. The main identified proteins adsorbed onto all PVA-SPION surfaces, irrespective of their surface charge or the incubation period, were BSA, which is known to acts as a "dys-opsonin", thus prolonging the circulation time of NPs in blood; ${ }^{51-53}$ alpha-2macrogloblulin, known to inhibit proteinases; ${ }^{54}$ serotransferrin and vitamin D-binding protein, important proteins in transport and trafficking; ${ }^{55,56}$ alpha-fetoprotein, which has a regulatory effect associated with the regulation of growth, differentiation, regeneration, and transformation in both ontogenetic and oncogenic growth processes; ${ }^{57}$ alpha-1B-glycoprotein, an immunoglobulin superfamily member whose biological function still remains unknown; $;^{58,59}$ alpha-1-antiproteinase, which is involved in blood coagulation ${ }^{54}$ and alpha-2-HS-gylcoprotein, which is involved in several functions, such as endocytosis, brain development and formation of bone tissue. ${ }^{54}$ Based on these observations it could be suggested that protein adsorption can be independent of the NP surface charge. ${ }^{60}$ Since many

Table 2 Common proteins found on the surface of all investigated PVA-SPIONs, irrespective of their surface charge and the time of incubation with $10 \%$ FBS

\begin{tabular}{llc}
\hline Identified proteins & Accession number & $M_{\mathrm{w}}(\mathrm{kDa})$ \\
\hline Alpha-2-macroglobulin & Q7SIH1 & 168 \\
Serotransferrin & Q29443 & 78 \\
Serum albumin & P02769 & 69 \\
Alpha-fetoprotein & Q3SZ57 & 69 \\
Alpha-1B-glycoproteins & Q2KJF1 & 54 \\
Vitamin D-binding protein & Q3MHN5 & 53 \\
Alpha-1-antiproteinase & P34955 & 46 \\
Alpha-2-HS-glycoprotein & P12763 & 38
\end{tabular}

abundant proteins bind to all three different surface charged PVA-SPIONs, the surface charge may no longer be the direct link to explain NP-cell interactions, but rather an important parameter for agglomeration studies which in turn may impact on NP uptake.

\section{NP-cell interactions}

In order to determine how the three different PVA-SPIONs interact with cellular systems, subsequent in vitro analysis was performed. HeLa cells were exposed to $100 \mu \mathrm{g}$ Fe per mL for up to $24 \mathrm{~h}$, and the NP uptake, in the form of the intracellular Fe content, was assessed via the Prussian Blue reaction assay (Fig. 2). The reliability of the Prussian blue reaction within in vitro systems has been highlighted as highly efficient. ${ }^{61}$ The results of the cellular Fe quantification showed that, over time, HeLa cells internalized p-PVA-SPIONs rapidly and to a greater extent than PVA or n-PVA-SPIONs.

The surface charge of NPs has always been highlighted as one of the most essential factors directly affecting the cellular uptake of NPs, due to the direct attack of the charged phospholipid head groups or protein domains on the cell surfaces by NPs. ${ }^{62}$ The preferential uptake of cationic agents has been widely discussed in the field of molecular biology, especially for transfection purposes. ${ }^{63}$ Using polymeric NPs Harush-Frenkel et al. suggested that the exposed charge significantly affects not only the internalization ability of NPs, but also the cellular endocytosis mechanism. In their study positively charged NPs were internalized rapidly via clathrin-mediated endocytosis and when this pathway was blocked, the NPs activated a compensatory endocytosis pathway that resulted in even higher accumulation of the positively charged NPs in cells. Negatively charged NPs showed an inferior rate of endocytosis and utilized the clathrin-mediated endocytosis pathway less. ${ }^{64}$ Neutral particles are known to have low cellular uptake rates. ${ }^{65,66}$

However, in this study the zeta potential of all three different PVA-SPIONs was found to be around $-12 \mathrm{mV}$ after incubation in the FBS supplemented cell culture medium (followed by magnetic separation and re-dispersions in water) irrespective of their initial surface potentials. This is consistent with previous reports that adsorption of serum proteins leads to a shift in the zeta potential to around $-16 \mathrm{mV} .^{60}$

\section{Colloidal stability}

In the context of electrostatic interactions, it has been reported that systems can lose their colloidal stability as BSA adsorption proceeds. ${ }^{67}$ Colloidal stability is a crucial factor with regard to any NP suspension, however the agglomeration of SPIONs not only reduces their superparamagnetic properties, ${ }^{68}$ but the size of the agglomerates may also influence the cellular effects of the particles in vitro and in vivo. ${ }^{69,70}$ TEM images of the p-PVASPIONs after incubation in the serum supplemented cell culture medium clearly show that they destabilize to a greater degree than the other two PVA-SPION types (Fig. 3). Micron sized agglomerates were observed for p-PVA-SPIONs, whereas smaller agglomerates were detected for PVA and n-PVA-SPIONs. However, this is only a qualitative comparison between NP 
Table 3 Proteins found on the surface of the investigated PVA-SPIONs, dependent on the particular surface charge of the PVA-SPIONs as well as the length of incubation time with $10 \%$ FBS

\begin{tabular}{|c|c|c|c|c|c|c|c|c|}
\hline \multirow[b]{3}{*}{ Identified proteins } & \multirow[b]{3}{*}{ Accession number } & \multirow[b]{3}{*}{$M_{\mathrm{w}}(\mathrm{kDa})$} & \multirow{2}{*}{\multicolumn{2}{|c|}{ 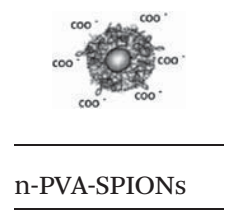 }} & \multirow{2}{*}{\multicolumn{2}{|c|}{ p-PVA-SPIONS }} & \multirow{2}{*}{\multicolumn{2}{|c|}{ PVA-SPIONs }} \\
\hline & & & & & & & & \\
\hline & & & $1 \mathrm{~h}$ & $16 \mathrm{~h}$ & $1 \mathrm{~h}$ & $16 \mathrm{~h}$ & $1 \mathrm{~h}$ & $16 \mathrm{~h}$ \\
\hline Complement C3 & Q2UVX4 & 187 & - & - & - & $\mathrm{x}$ & - & - \\
\hline Hemopexin & Q3SZV7 & 52 & - & $\mathrm{x}$ & - & $\mathrm{x}$ & - & - \\
\hline Anti-thrombin III & $\mathrm{P} 41361$ & 52 & - & $\mathrm{x}$ & - & - & - & - \\
\hline Angiotensinogen & P20757 & 51 & - & - & $\mathrm{x}$ & - & $\mathrm{x}$ & - \\
\hline Apolipoprotein A1 & P15497 & 30 & - & - & - & - & $\mathrm{x}$ & - \\
\hline
\end{tabular}

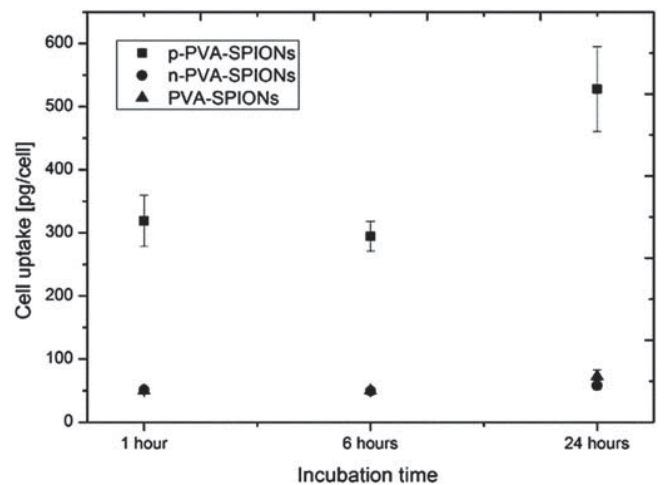

Fig. 2 Cellular uptake of the investigated PVA-SPIONs. The amount of NPs present within HeLa cells is presented as a function of incubation time after NP exposure at a concentration of $100 \mu \mathrm{g}$ Fe per $\mathrm{mL}$ in 10\% FBS supplemented cell culture media.

types, as it is possible that artifacts from the drying process on TEM grids are present, complementary light scattering measurements were performed.

Light scattering and UV-Vis spectroscopy can provide an insight into the size, polydispersity and concentrations of any agglomerates present. The standard method of particle sizing at one angle by DLS, via a cumulants analysis, can lead to incorrect conclusions for either multimodal or highly polydisperse samples. This is evident from Fig. $4 \mathrm{~A}$ for the p-PVA-SPIONs where the hydrodynamic radius at high $q$ is considered - it indicates a size less than twice that of the other samples. It was also found that the presence of polymers, proteins, agglomerates and individual particles means that often the CONTIN algorithms give size distributions which were not reproducible over many angles. Therefore, a comparison of the hydrodynamic radius as a function of the scattering vector $(q$, related to the scattering angle) was performed, allowing predictions of the size and polydispersity of the samples.

Fig. 4A shows the average hydrodynamic radius of the particles against the modulus of the scattering vector after $6 \mathrm{~h}$ of incubation in FBS at $37{ }^{\circ} \mathrm{C}$, calculated using a cumulants analysis where the error bars correspond to the standard deviation of the mean from three individual samples. Here, a cumulants analysis is solely indicative of sizes through measuring at many angles. The p-PVA-SPIONs were shown to be significantly agglomerated as indicated by the larger size and change with scattering vector, while all samples were relatively polydisperse $(45 \%, 41 \%$ and $37 \%$ polydispersity for the PVASPIONs, p-PVA-SPIONs and n-PVA-SPIONs, respectively). At the lowest angle, mean diameters larger than $500 \mathrm{~nm}$ were measured for the p-PVA-SPIONs. The change in the hydrodynamic radius with scattering angle may be due to the form factor and increased forward scattering of the larger polydisperse agglomerates (Mie scattering, where the particles size is comparable to the laser wavelength) meaning the signal from smaller Rayleigh scatterers (considerably smaller than the laser wavelength) is swamped.

These conclusions are supported by the static light scattering (SLS) measurements (Fig. 4B), which shows an increased scattering intensity at low $q$ (low angles), characteristic of the presence of larger NPs or agglomerates. The hydrodynamic radius of the PVA-SPIONs and n-PVA-SPIONs, in the presence of serum, displayed minor changes with the scattering angle indicating minimal agglomeration. Additionally, few changes in the size were observed for any sample between 6 and $24 \mathrm{~h}$, signifying the colloidal stability of the agglomerates once formed.

The above findings are further confirmed in the scattered intensity curves (Fig. 4B), with an upturn at low angles for the pPVA-SPIONs. There was also no decrease in the scattered intensity between 6 and $24 \mathrm{~h}$, meaning sedimentation of the agglomerates did not occur. It has been recently shown that the type of agglomerates, either densely or loosely structured (as defined by their fractal dimension), can impact on the cellular response. ${ }^{71}$ The fractal dimension was calculated at values of $q$ corresponding to the size range $300-950 \mathrm{~nm}$, intermediate for the aggregates allowing us to probe their internal structure. The p-PVA-SPIONs had fractal dimensions of 1.6 and 1.5 after $6 \mathrm{~h}$ and $24 \mathrm{~h}$ incubation periods, respectively. Both these values are indicative of an open structure formed by diffusion limited cluster agglomeration. Recently, Schaeublin et al. reported that gold agglomerates with a low fractal dimension can induce cytotoxicity compared to agglomerates with a higher fractal dimension in HaCaT cells. ${ }^{71}$ However, in the present study, no 

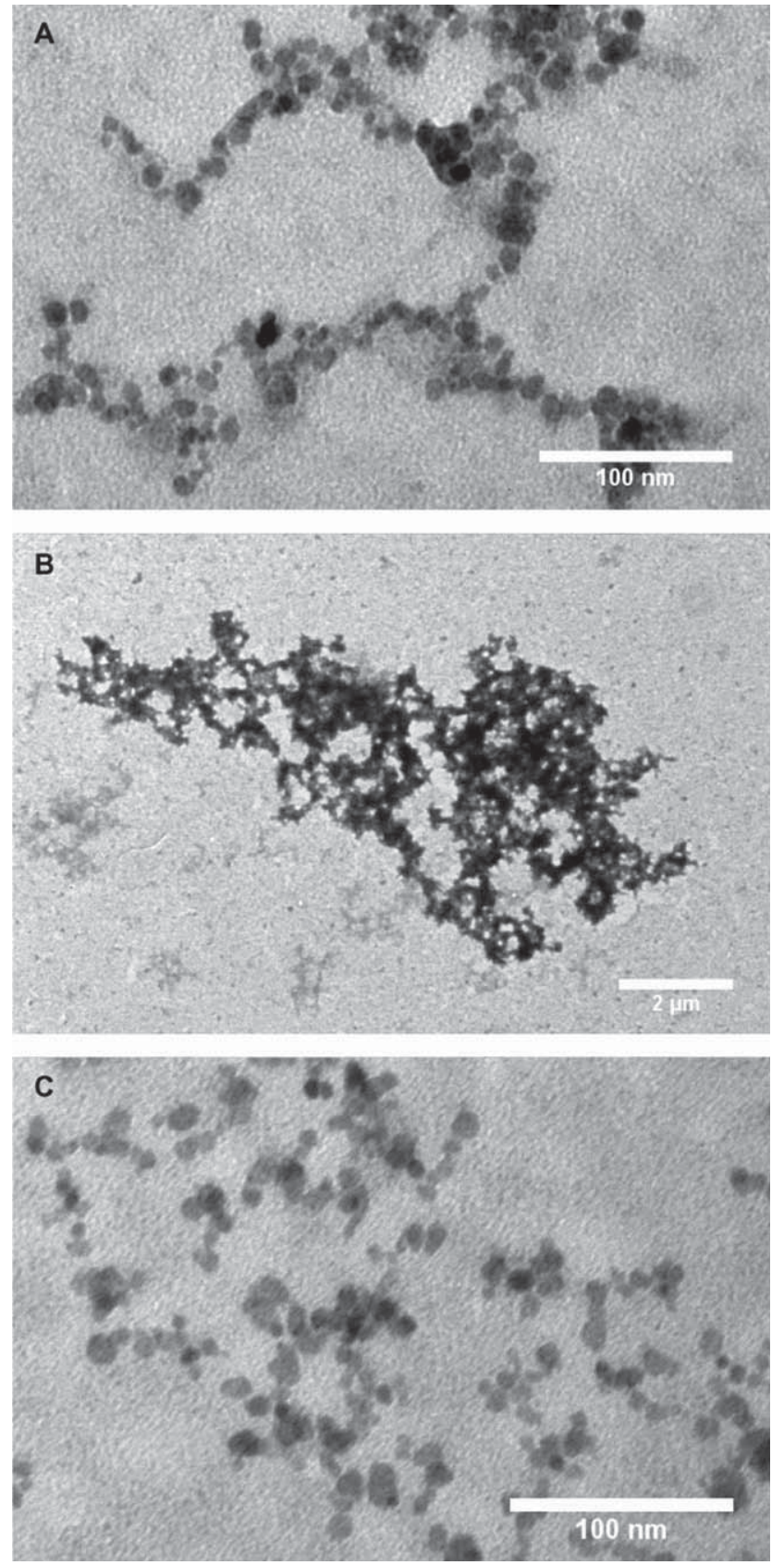

Fig. 3 Transmission electron microscopy images of PVA-SPIONs after incubation in cell culture media supplemented with 10\% FBS. (A) PVA-SPIONs, (B) p-PVASPIONs and (C) n-PV-SPIONs.

cytotoxicity in HeLa cells, as measured by the release of the cytosolic enzyme lactate dehydrogenase, was observed for the agglomerated p-PVA-SPIONs with low fractal dimensions over a $24 \mathrm{~h}$ period up to $100 \mu \mathrm{g}$ Fe per mL (Fig. S3, ESI $\dagger$ ).

\section{Sedimentation}

The observation that the p-PVA-SPIONs show a higher uptake within the HeLa cells compared to the PVA-SPIONs and n-PVASPIONs could be due to sedimentation of larger NPs or agglomerates in the cell culture plate. This leads to a locally higher concentration on the cell surface than initially applied,
A

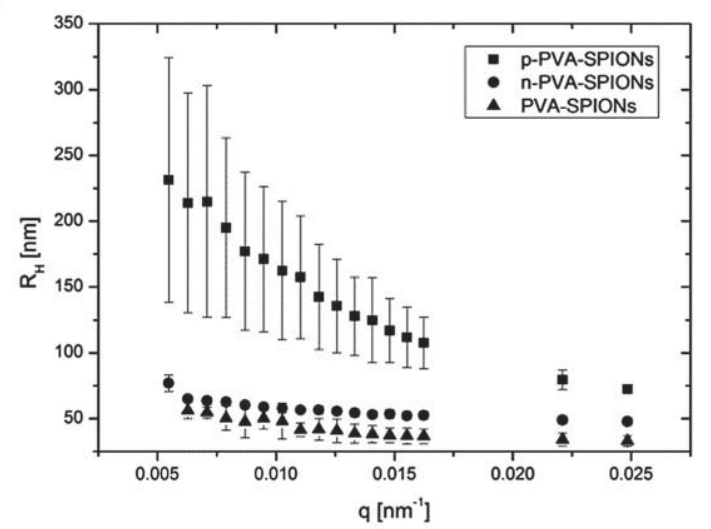

B

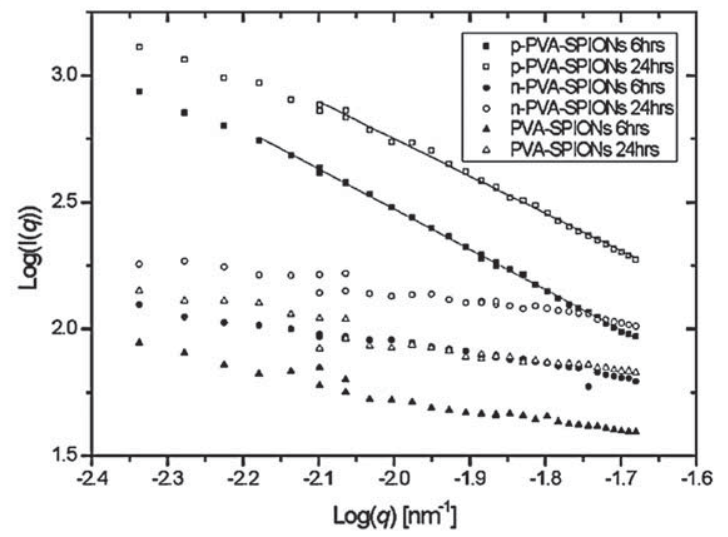

Fig. 4 Light scattering of different charged PVA-SPIONs in cell culture media supplemented with $10 \%$ FBS. (A) The hydrodynamic radius vs. scattering vector of the PVA-SPIONs after $6 \mathrm{~h}$ of incubation with $10 \%$ FBS. (B) The scattered intensity vs. scattering vector after 6 and $24 \mathrm{~h}$ of incubation with $10 \%$ FBS.

causing a higher misrepresentative cellular uptake. Hinderliter et al. considered the effect of sedimentation and diffusion of NPs in regards to their dosimetry from a theoretical perspective, and further showed that dose-rates and target cell doses are not equal for all NP types. ${ }^{72}$ Teeguarden et al. developed and applied the principles of dosimetry in vitro and outlined an approach for simulation of "particokinetics" in cell culture systems. ${ }^{24}$ Furthermore, Cho et al. measured the number of gold NPs taken up by cells in both an upright and inverted configuration and demonstrated that gold NPs can sediment faster and thus greater difference in cellular uptake between the two configurations for this particular NP type. ${ }^{23}$

Considering the scattering intensities presented in Fig. 4B (i.e. there was no decrease over a period of 24 hours), only a minimal sedimentation rate could be associated with the p-PVA-SPIONs. However, it is feasible that the largest agglomerates sediment while the smaller particles form more agglomerates leading to a minor change in the scattering patterns. This is assumed to be unlikely with this NP type due to a lower density profile of PVA-SPIONs compared to gold or other dense materials. Nevertheless, further analysis was performed by UV-Vis spectroscopy, where the absorbance at $400 \mathrm{~nm}$ was converted to a concentration via a standard curve for the 
p-PVA-SPIONs incubated in FBS at $37^{\circ} \mathrm{C}$ and the concentration was monitored over $24 \mathrm{~h}$ (Fig. S4 and S5, ESI $\dagger$ ). Again, no decrease was observed, signifying that the p-PVA-SPION agglomerates are stable in suspension. To evaluate whether this is reasonable, the ratio of velocity of sedimentation to velocity of diffusion was calculated to be 0.9 , which is below the threshold value of 3 found for sedimentation to become important (Calculation of sedimentation parameters, ESI $\dagger$ ). ${ }^{23}$ Therefore, from these observations, it can be confirmed that sedimentation is not the reason for the $20-50 \%$ enhanced cellular uptake of p-PVA-SPIONs. The difference between this finding and the findings of Cho et al. can therefore be associated with the difference in the specific material of the NP.

Since sedimentation could not be attributed to the increased cellular uptake of the p-PVA-SPIONs by the HeLa cells, an alternative explanation of the observed phenomenon could be the specific active uptake mechanism by which the different PVA-SPIONs are engulfed by the HeLa cells. ${ }^{73}$ Whilst it is necessary to highlight that epithelial cells have limited phagocytic properties compared to other cells (i.e. macrophage cells), it has previously been shown that epithelial cells, independent of their organ of origin, can elicit the active uptake of NPs. ${ }^{74}$ Recently, Brandenberger et al. suggested that macropinocytosis may be the predominant uptake mechanism of gold NP aggregates compared to caveolin- and clathrin-mediated endocytosis of single NPs stabilized with polyethyleneglycol (PEG) by studying their internalisation by the lung carcinoma cell line A549. ${ }^{75}$ Furthermore, Albanese and Chan evaluated the effect of size of actively targeting transferrin-coated gold nanoparticle aggregates on their uptake kinetics and the subsequent biological impact on HeLa and A549 epithelial cells, as well as MDA-MB-435 carcinoma cells which expressed varying levels of the target receptor. ${ }^{76}$ It was observed that, depending on the cell type, multiple cell responses were possible when NPs aggregate. The notion that cells, of any type, may initiate the onset of multiple uptake mechanisms has been suggested previously; however limited research has been performed to support this hypothesis. ${ }^{77}$ Theoretically, it is feasible that cells could undergo different active processes at the same time. ${ }^{63}$

Unless stereological analyses for the quantitative assessment of particle uptake are carried out, uptake data are usually obtained from photometric assays or inductively coupled plasma optical emission spectrometry. Both techniques rely on the chemical dissolution of NPs and only measure the mass of, in our case, iron per cell, which is then converted to number of particles per cell thereby assuming monodisperse single (i.e. nonaggregated) particles, which is not always the case. From reported findings and those of the present study, it can be concluded that a combination of a multitude of parameters $(e . g$. size, surface, protein adsorption, particle quantification and intracellular localisation, cell type and exposure route) has to be taken into consideration when evaluating NP-cell interactions and that the state of dispersion (described by the quantification of agglomerates for size, number of particles, strength of interparticle forces, shape and distribution of the agglomerates in the system) will have to be taken into account in future studies.

\section{Experimental}

\section{Chemicals and reagents}

All chemicals and reagents were purchased from Sigma Aldrich, Switzerland unless otherwise stated. All chemicals were of analytical reagent grade and were used without further purification. Water refers in all synthesis steps to ultrapure deionized water of $18 \Omega \mathrm{S} \mathrm{cm}^{-1}$ (Millipore AG, Switzerland). The serum used was EU approved fetal bovine serum (FBS) originating from a singular batch (reference no. 10270106, lot no. 41G8582K, Invitrogen, Switzerland). The Certificate of Analysis provided by Invitrogen showed that bovine serum albumin constitutes $52 \%$ (i.e. $1.91 \mathrm{~g} \mathrm{dl}^{-1}$ ) of the total protein content (i.e. $3.62 \mathrm{~g} \mathrm{dl}^{-1}$ ) present in the FBS.

\section{Synthesis of PVA coated SPIONs}

Superparamagnetic iron oxide nanoparticles (SPIONs) were prepared by alkaline co-precipitation of ferric and ferrous chlorides in aqueous solution as described previously. ${ }^{39-41}$ The subsequent suspension was then dialyzed against $0.01 \mathrm{M}$ nitric acid for 2 days and stored at $4{ }^{\circ} \mathrm{C}$. Polyvinyl alcohol (PVA) with an average molecular weight $\left(M_{\mathrm{w}}\right)$ of $14000 \mathrm{~g} \mathrm{~mol}^{-1}$ and a hydrolysis degree of $83 \%$ was supplied by Omya AG, Switzerland (Mowiol 3-83). Vinylalcohol-vinylamine copolymer, with an average $M_{\mathrm{w}}$ of $80000-140000$, was supplied by Erkol S.A, Spain (M12) and carboxyl-modified PVA was supplied by Kuraray Specialties Europe GmbH, Germany (KL506). Polymer solutions were prepared by dissolving the powders in water $(10 \% \mathrm{w} / \mathrm{v}$ Mowiol 3-83, 2\% w/v M12 and 6\% w/v KL506), followed by rapidly heating the solutions for $15 \mathrm{~min}$ (Mowiol 3-83 and KL506) and $4 \mathrm{~h}$ (M12) at $90{ }^{\circ} \mathrm{C}$. In order to obtain PVA coated SPIONs of different surface charges the NP suspension was mixed in a v/v ratio of 1 with different polymer solutions. The $\mathrm{pH}$ of the final suspensions was adjusted to 7 using a $5 \%$ aqueous ammonia solution.

\section{Transmission Electron Microscopy (TEM)}

TEM was performed using a Morgani conventional transmission electron microscope operating at $80 \mathrm{kV}$. Images were assessed at a magnification of 71000 . Samples were prepared by allowing the PVA-SPION suspensions, at a concentration of $25 \mu \mathrm{g}$ Fe per $\mathrm{mL}$, to dry at room temperature on carbon-coated copper grids.

\section{Fe quantification}

To determine the concentration of the NP suspension, the amount of Fe present in the uncoated SPION suspension was quantified by (i) titration with potassium permanganate, as previously described by Skoog et al. $^{42}$ and (ii) the Prussian blue colorimetric assay. Briefly, the Prussian blue assay was conducted with $100 \mu \mathrm{L}$ of various concentrations (12.5 to $50 \mu \mathrm{g}$ ) $\left(\mathrm{H}_{2} \mathrm{O}\right.$ served as the negative control) of the uncoated SPIONs being dissolved for $1 \mathrm{~h}$ in $6 \mathrm{~N} \mathrm{HCl}$ (Honeywell Burdick \& Jackson) (50 $\mu \mathrm{L}$ per well of a 96-well plate). Subsequently, $50 \mu \mathrm{L}$ of $5 \% \mathrm{~K}_{4}\left[\mathrm{Fe}(\mathrm{CN})_{6}\right]$ (Merck, Switzerland) was added to each well. The absorbance was then determined at a wavelength of $690 \mathrm{~nm}$ 
using a multi-label plate reader (Victor3, PerkinElmer, Switzerland) $(n=3)$.

\section{Particle characterization by Photon Correlation Spectroscopy (PCS)}

The physicochemical parameters of the polymer coated SPIONs, specifically the size and zeta-potential, were assessed via light-scattering measurements at $90^{\circ}$ by PCS (Brookhaven Instruments Cooperation, LABORCHEMIE GmbH, Austria; equipped with a BI-9000AT digital autocorrelator). The CONTIN method was used for data processing. The different PVASPION suspensions were diluted in a $20 \mathrm{mM}$ borate buffer solution at $\mathrm{pH} 7.5$ to concentrations of $30 \mu \mathrm{g}$ Fe per $\mathrm{mL}, 50 \mu \mathrm{g}$ Fe per $\mathrm{mL}$ and $100 \mu \mathrm{g}$ Fe per mL (size) and to a concentration of $100 \mu \mathrm{g}$ Fe per $\mathrm{mL}$ (zeta-potential) prior to analysis. The theoretical refractive index of 2.42 of magnetite was used to calculate the number-weighted distribution from the raw-intensity weighted data. ${ }^{43}$ Zeta-potential measurements were performed using the same setting, equipped with a platinum electrode. The Smoluchowski method was chosen for data processing. The viscosity, refractive index and dielectric constant of pure water were used to characterize the solvent.

\section{Incubation of SPIONs with serum (FBS)}

The NPs were incubated with a $10 \%$ FBS solution in $1 \times$ Phosphate Buffered Saline (PBS) (Invitrogen, Switzerland) for 1 and $16 \mathrm{~h}$.

\section{Magnetic separation using a magnetic fixed bed reactor}

To elute the adsorbed proteins from the NPs the latter were immobilized in a magnetic fixed bed reactor as described previously by Steitz et $a l .{ }^{44}$ In accordance with the KirkwoodBuff theory ${ }^{45}$ the adsorbed proteins were eluted by means of aqueous solutions of $\mathrm{KCl}$ (Sigma Aldrich, Switzerland). In order to observe any differences in protein affinity towards the NP surface, two solutions of different salt concentrations were used to elute the adsorbed proteins. The system was connected to a vacuum pump (HPLC 420, Kontron Instruments, Switzerland) and the proteins were eluted at a flow of $0.5 \mathrm{~mL} \mathrm{~min} \mathrm{~m}^{-1}$. In a first step, $6 \mathrm{~mL}$ of a $50 \mathrm{mM}$ aqueous $\mathrm{KCl}$ solution led to the fall through fraction ("FT") and the elution fractions (E) "E1" to "E5", each of a volume of $1 \mathrm{~mL}$. In a second step, $5 \mathrm{~mL}$ of a 100 $\mathrm{mM}$ aqueous $\mathrm{KCl}$ solution were used to elute stronger bound proteins, leading to the elution fractions "E6" to "E10", each of a volume of $1 \mathrm{~mL}$.

\section{Sample preparation for 1D SDS-PAGE}

Proteins were precipitated with $500 \mu \mathrm{L}$ of a $4{ }^{\circ} \mathrm{C}$ cold $221 \% \mathrm{w} / \mathrm{v}$ aqueous solution of trichloroacetic acid per $\mathrm{mL}$ of eluant and centrifuged at $25000 \mathrm{~g}$ for $30 \mathrm{~min}$ at $4{ }^{\circ} \mathrm{C}$. The supernatant was then removed, and the procedure was repeated with $500 \mu \mathrm{L}$ acetone at $4{ }^{\circ} \mathrm{C}$. The obtained pellet was subsequently dissolved in $100 \mu \mathrm{L}$ ReadyPrep 2-D Rehydration/Sample Buffer 1 (Bio-Rad, Switzerland). The same volumes of $10 \mu \mathrm{L}$ of each sample solution were mixed in a v/v ratio of 1 with Laemmli Sample Buffer (Bio-Rad, Switzerland) and boiled for $5 \mathrm{~min}$ before loading into the wells of $12.5 \%$ SDS-PAGE gels. The pre-stained Precision Plus Protein ${ }^{\mathrm{TM}}$ Dual Colour Standard (Bio-Rad, Switzerland) served as a molecular weight marker.

\section{D SDS-PAGE}

Proteins were separated via electrophoresis according to their size at a constant current of $150 \mathrm{~V}$. Proteins were then fixed in an aqueous solution of $50 \%$ of ethanol, $12 \%$ of acetic acid and 0.5 $\mathrm{mL} / \mathrm{L}$ of $37 \%$ formaldehyde. Proteins were then stained overnight with Coomassie Brilliant Blue R-250 staining solution (Bio-Rad, Switzerland). Gels were then stored in water at $4{ }^{\circ} \mathrm{C}$ until mass spectrometry analysis could occur.

\section{Protein identification by Mass Spectrometry (MS)}

MS measurements were carried out at the Proteomics Core Facility of the École polytechnique fédérale de Lausanne (EPFL, Switzerland). Bands of interest were excised from SDS-PAGE gels and sample preparation was carried out by means of in-gel trypsin digestion according to an in house protocol. The resulting peptide mixtures were re-suspended in $98 \% \mathrm{H}_{2} \mathrm{O}, 2 \%$ acetonitrile and $0.1 \%$ formic acid and then analyzed by nanoelectrospray liquid chromatography mass spectrometry (ESI + LC MS/MS). Samples were first separated by high-performance liquid chromatography (HPLC) (Reverse Phase, C18) and masses of eluting peptides as well as fragmentation patterns were measured online using a Thermo LTQ ion trap mass spectrometer (linear trap quadrupole, Thermo Scientific, Switzerland). Chromatography buffer solutions (Buffer A: $98 \% \mathrm{H}_{2} \mathrm{O}$, $2 \%$ acetonitrile and $0.1 \%$ formic acid; Buffer B: $100 \%$ acetonitrile and $0.1 \%$ formic acid) were used to deliver a $60 \mathrm{~min}$ gradient (Biphasic gradient from 99\% Buffer A to 90\% Buffer B). Samples were loaded on a homemade $100 \mu \mathrm{m}$ ID $\times 020 \mathrm{~mm}$ C18 pre-column (Magic C18, $3 \mu \mathrm{L}$ beads and $200 \AA$ pore size) and separation was performed at $400 \mathrm{~nL} \min ^{-1}$ using again a homemade $75 \mu \mathrm{m}$ ID $\times 100 \mathrm{~mm}$ C18 separation micro-column (Magic C18, $3 \mu \mathrm{m}$ beads and $100 \AA$ pore size) and data were processed using Proteome Discoverer 1.1 (Thermo) and Mascot 2.3 as the search engine. Outputs were then displayed using Scaffold 3 and $\mathrm{X}$ tandem cross-validation was applied during reprocessing. The used database was the September 2010 version of SwissProt database (http://www.expasy.org), including the reversed version.

\section{Evaluation of MS-Data}

To validate the MS/MS based peptide and protein identifications, the computer software Scaffold (version Scaffold 3.1.2, Proteome Software Inc., Portland, OR) was used. Peptide identifications were only accepted if they could be established as having a $>90.0 \%$ probability as specified by the Peptide Prophet algorithm. ${ }^{46}$ Protein identifications were accepted only if they could be established as having a $>90.0 \%$ probability and contained at least two identified peptides. Protein probabilities were assigned by the Protein Prophet algorithm. ${ }^{47}$ 


\section{Cell-culture}

Human cervix carcinoma cells (HeLa cells) were purchased from HPA Culture Collections, UK and cultured in a $75 \mathrm{~cm}^{2}$ cell culture flask using $1 \times$ Dulbecco's Modified Eagle Medium (DMEM, Invitrogen, Switzerland) supplemented with 10\% FBS and $1 \%$ penicillin/streptomycin (Invitrogen, Switzerland) at $37^{\circ} \mathrm{C}$ and $5 \% \mathrm{CO}_{2}$. At $24 \mathrm{~h}$ prior to experimentation cells were detached using Trypsin-EDTA (Invitorgen, Switzerland) and their viability was determined via Trypan blue exclusion. In a 48 well-plate (Costar, Corning Incorporated, USA), HeLa cells were seeded at a density of $2.5 \times 10^{4}$ cells per well and were cultured at $37{ }^{\circ} \mathrm{C}$ and $5 \% \mathrm{CO}_{2}$ for $24 \mathrm{~h}$ prior to NP exposure.

\section{NP exposure}

Prior to NP exposure cells were washed with $1 \times$ PBS and the supplemented medium changed. PVA-SPIONs, p-PVA-SPIONs and n-PVA-SPIONs were added at a concentration of $100 \mu \mathrm{g}$ $\mathrm{mL}^{-1}$ of Fe diluted in $10 \%$ FBS supplemented cell culture media and incubated for 1,6 and $24 \mathrm{~h}$ at $37{ }^{\circ} \mathrm{C}$ and $5 \% \mathrm{CO}_{2}$. Supplemented cell culture media only acted as the negative control.

\section{Cellular uptake determination by cellular Fe quantification}

The ability of each PVA-SPION type to enter HeLa cells after 1, 6 and $24 \mathrm{~h}$ of exposure at $100 \mu \mathrm{g}$ Fe per mL was determined using the Prussian Blue assay as previously described. Briefly, after exposure to PVA-SPIONs the cell layer was dissolved in $6 \mathrm{~N} \mathrm{HCl}$ (100 $\mu \mathrm{L}$ per well of a 48 -well plate) for $1 \mathrm{~h}$, then $50 \mu \mathrm{L}$ per well of a $5 \%$ solution of $\mathrm{K}_{4}\left[\mathrm{Fe}(\mathrm{CN})_{6}\right]$ (Merck, Switzerland) in $\mathrm{H}_{2} \mathrm{O}$ was added for $10 \mathrm{~min}$ and the absorbance measured at $690 \mathrm{~nm}$ using a multilabel plate reader (Victor3, PerkinElmer, Switzerland). A standard curve of the differently coated SPIONs was recorded to quantify the amount of Fe inside cells. The Fe content in cells not exposed to SPIONs was always below the detection limit of $1 \mathrm{ppm}$. Each experiment was performed in triplicate $(n=3)$.

\section{Static and dynamic light scattering}

The colloidal stability and agglomeration state of the NP dispersion were concurrently analyzed using a 3D LS spectrometer (LS Instruments). All three different NPs used here (i.e. PVA-SPIONs, p-PVA-SPIONs, and n-PVA-SPIONs) were incubated in $10 \%$ FBS supplemented cell culture media for 6 and $24 \mathrm{~h}$ in a $5 \mathrm{~mm}$ borosilicate NMR tube at $37{ }^{\circ} \mathrm{C}$. Measurements were performed at $20^{\circ}$ to $104^{\circ}$ with a $3^{\circ}$ increment $(30 \mathrm{~s}$ collection time and three repetitions per angle). At every angle, the cumulants analysis was performed on the correlation function and the mean intensity collected for static light scattering interpretation.

\section{Conclusions}

In this study, different surface charged polyvinyl alcohol coated SPIONs were synthesized and characterized. Upon incubation in supplemented cell culture media very similar adsorbed protein profiles were identified. However, the incubation time played an important role in protein adsorption. Despite the comparable protein corona, which was also confirmed by similar zeta potential values after serum incubation, cellular uptake of p-PVA-SPIONs was significantly faster and higher compared to both PVA-SPIONs and n-PVA-SPIONs. However, p-PVA-SPIONs elicited a much lower colloidal stability than nand PVA-SPIONs, promoting a higher non-sedimentation driven penetration of p-PVA-SPIONs in vitro without any significant cytotoxic effects. These results underline the importance of understanding the aggregation state of NPs in biological fluids. On-going research will help to better understand the mechanisms of cellular uptake of naturally occurring agglomerates of NPs used for medical applications.

\section{Conflict of interest}

The authors declare no conflicts of interest. The authors are entirely responsible for the writing of the manuscript and its content.

\section{Acknowledgements}

The authors would like to thank Diego Chiappe (Proteomic Core Facility of the École polytechnique fédérale de Lausanne (EPFL, Switzerland)) for his help with the LC-MS/MS measurements. The authors also acknowledge the funding provided by the Swiss National Science Foundation (PP00P2-123373/1 and 122355), the Adolphe Merkle Foundation, the University of Fribourg and FriMat (Fribourg Center for Nanomaterials).

\section{Notes and references}

1 K. Riehemann, S. W. Schneider, T. A. Luger, B. Godin, M. Ferrari and H. Fuchs, Angew. Chem., Int. Ed., 2009, 48(5), 872 .

2 M. Beija, R. Salvayre, N. Lauth-de Viguerie and J.-D. Marty, Trends Biotechnol., 2012, 30(9), 485.

3 K. Donaldson, Occup. Environ. Med., 2004, 61(9), 727.

4 G. Oberdörster, E. Oberdörster and J. Oberdörster, Environ. Health Perspect., 2005, 113(7), 823.

5 J. Klein, Proc. Natl. Acad. Sci. U. S. A., 2007, 104(7), 2029.

6 W. Jiang, B. Y. S. Kim, J. T. Rutka and W. C. W. Chan, Nat. Nanotechnol., 2008, 3(3), 145.

7 E. C. Cho, J. Xie, P. A. Wurm and Y. Xia, Nano Lett., 2009, 9(3), 1080.

8 E. C. Cho, L. Au, Q. Zhang and Y. Xia, Small, 2010, 6(4), 517. 9 A. Verma and F. Stellacci, Small, 2010, 6(1), 12.

10 K. Unfried, C. Albrecht, L.-O. Klotz, A. von Mikecz, S. Grether-Beck and R. P. Schins, Nanotoxicology, 2007, 1(1), 52.

11 A. Petri-Fink, M. Chastellain, L. Juillerat-Jeanneret, A. Ferrari and H. Hofmann, Biomaterials, 2005, 26(15), 2685.

12 A. E. Nel, L. Mädler, D. Velegol, T. Xia, E. M. V. Hoek, P. Somasundaran, F. Klaessig, V. Castranova and M. Thompson, Nat. Mater., 2009, 8(7), 543.

13 I. Lynch, A. Salvati and K. A. Dawson, Nat. Nanotechnol., 2009, 4(9), 546. 
14 R. C. Murdock, L. Braydich-Stolle, A. M. Schrand, J. J. Schlager and S. M. Hussain, Toxicol. Sci., 2008, 101(2), 239.

15 D. B. Warheit, Toxicol. Sci., 2008, 101(2), 183.

16 T. Cedervall, I. Lynch, M. Foy, T. Berggard, S. Donnelly, G. Cagney, S. Linse and K. Dawson, Angew. Chem., Int. Ed., 2007, 46(30), 5754.

17 M. Lundqvist, J. Stigler, G. Elia, I. Lynch, T. Cedervall and K. A. Dawson, Proc. Natl. Acad. Sci. U. S. A., 2008, 105(38), 14265.

18 D. E. Owens and N. A. Peppas, Int. J. Pharm., 2006, 307(1), 93.

19 M. Roser, D. Fischer and T. Kissel, Eur. J. Pharm. Biopharm., 1998, 46(3), 255.

20 M. J. D. Clift, P. Gehr and B. Rothen-Rutishauser, Arch. Toxicol., 2011, 85(7), 723.

21 P. Aggarwal, J. B. Hall, C. B. McLeland, M. A. Dobrovolskaia and S. E. McNeil, Adv. Drug Delivery Rev., 2009, 61(6), 428.

22 J. Adair, E. Suvaci and J. Sindel, in Encyclopedia of Materials: Science and Technology, Elsevier Publishing, The Netherlands, 2001, p. 8996.

23 E. C. Cho, Q. Zhang and Y. Xia, Nat. Nanotechnol., 2011, 6(6), 385.

24 J. G. Teeguarden, P. M. Hinderliter, G. Orr, B. D. Thrall and J. G. Pounds, Toxicol. Sci., 2006, 95(2), 300.

25 C. Xu, G. A. Tung and S. Sun, Chem. Mater., 2008, 20(13), 4167.

26 M. Mahmoudi, H. Hofmann, B. Rothen-Rutishauser and A. Petri-Fink, Chem. Rev., 2012, 112(4), 2323.

27 C. C. Berry and A. S. G. Curtis, J. Phys. D: Appl. Phys., 2003, 36(13), R198-R206.

28 S. Laurent, D. Forge, M. Port, A. Roch, C. Robic, L. Vander Elst and R. N. Muller, Chem. Rev., 2008, 108(6), 2064.

29 Q. A. Pankhurst, J. Connolly, S. K. Jones and J. Dobson, J. Phys. D: Appl. Phys., 2003, 36(13), R167-R181.

30 A. Petri-Fink and H. Hofmann, IEEE Trans. NanoBiosci., 2007, 6(4), 289.

31 C. Sun, J. Lee and M. Zhang, Adv. Drug Delivery Rev., 2008, 60(11), 1252.

32 L. Frullano and T. J. Meade, JBIC, J. Biol. Inorg. Chem., 2007, 12(7), 939.

33 C. Corot, P. Robert, J. Idee and M. Port, Adv. Drug Delivery Rev., 2006, 58(14), 1471.

34 J. Dobson, Drug Dev. Res., 2006, 67(1), 55.

35 J. Durán, J. Arias, V. Gallardo and A. Delgado, J. Pharm. Sci., 2008, 97(8), 2948.

36 A. Solanki, J. D. Kim and K.-B. Lee, Nanomedicine, 2008, 3(4), 567.

37 B. Thiesen and A. Jordan, Int. J. Hyperthermia, 2008, 24(6), 467.

38 O. Veiseh, J. W. Gunn and M. Zhang, Adv. Drug Delivery Rev., 2010, 62(3), 284.

39 M. Chastellain, A. Petri and H. Hofmann, J. Colloid Interface Sci., 2004, 278(2), 353.

40 E. García-Matres, J. Magn. Magn. Mater., 1995, 149(3), 363.

41 G. van Ewijk, J. Magn. Magn. Mater., 1999, 201(1-3), 31.
42 D. A. Skoog, D. M. West and F. J. Holler, Fundamentals of Analytical Chemistry, Saunders College Pub., Fort Worth, 1996.

43 R. M. Cornell and U. Schwertmann, The Iron Oxides: Structure, Properties, Reactions, Occurrences and Uses, WileyVCH, Weinheim [u.a.], 2006.

44 B. Steitz, J. Salaklang, A. Finka, C. O'Neil, H. Hofmann and A. Petri-Fink, Bioconjugate Chem., 2007, 18(5), 1684.

45 V. Pierce, M. Kang, M. Aburi, S. Weerasinghe and P. E. Smith, Cell Biochem. Biophys., 2008, 50(1), 1.

46 A. Keller, A. I. Nesvizhskii, E. Kolker and R. Aebersold, Anal. Chem., 2002, 74(20), 5383.

47 A. I. Nesvizhskii, A. Keller, E. Kolker and R. Aebersold, Anal. Chem., 2003, 75(17), 4646.

48 T. Cedervall, I. Lynch, S. Lindman, T. Berggard, E. Thulin, H. Nilsson, K. A. Dawson and S. Linse, Proc. Natl. Acad. Sci. U. S. A., 2007, 104(7), 2050.

49 H. Kurz, H. Trunk and B. Weitz, Arzneimittelforschung, 1977, $27(7), 1373$.

50 K. Thode, M. Lück, W. Semmler, R. H. Müller and M. Kresse, Pharm. Res., 1997, 14(7), 905.

51 T. Goppert and R. Mueller, Eur. J. Pharm. Biopharm., 2005, 60(3), 361.

52 I. S. Muir, L. Illum, S. S. Davis and V. Kolb-Bachofen, Biochim. Biophys. Acta, Mol. Cell Res., 1993, 1179(2), 157.

53 K.-i. Ogawara, K. Furumoto, S. Nagayama, K. Minato, K. Higaki, T. Kai and T. Kimura, J. Controlled Release, 2004, $100(3), 451$.

54 The Universal Protein Resource (UniProt, http://www. uniprot.org).

55 A. Castellano, M. Barteri, M. Castagnola, A. Bianconi, E. Borghi and S. Dellalonga, Biochem. Biophys. Res. Commun., 1994, 198(2), 646.

56 P. T. Gomme and J. Bertolini, Trends Biotechnol., 2004, 22(7), 340.

57 M. S. Li, P. F. Li, F. Y. Yang, S. P. He, G. G. Du and G. Li, Cell Res., 2002, 12(2), 151.

58 L. Udby, A. H. Johnsen and N. Borregaard, Biochim. Biophys. Acta, Gen. Subj., 2010, 1800(4), 481.

59 A. Stratil, P. Kaláb and R. Pokorný, Comp. Biochem. Physiol., Part B: Biochem. Mol. Biol., 1988, 91(4), 783.

60 S. Tenzer, D. Docter, S. Rosfa, A. Wlodarski, J. Kuharev, A. Rekik, S. K. Knauer, C. Bantz, T. Nawroth, C. Bier, J. Sirirattanapan, W. Mann, L. Treuel, R. Zellner, M. Maskos, H. Schild and R. H. Stauber, ACS Nano, 2011, 5(9), 7155.

61 F. Timm, Histochem. Cell Biol., 1960, 2(2), 143.

62 C. C. Fleck and R. R. Netz, Europhys. Lett., 2004, 67(2), 314.

63 B. Alberts, Molecular Biology of the Cell, Garland Science, New York, NY, 2002.

64 O. Harush-Frenkel, N. Debotton, S. Benita and Y. Altschuler, Biochem. Biophys. Res. Commun., 2007, 353(1), 26.

65 J. Xie, C. Xu, N. Kohler, Y. Hou and S. Sun, Adv. Mater., 2007, 19(20), 3163.

66 B.-S. Kim, C.-S. Kim and K.-M. Lee, Arch. Pharmacal Res., 2008, 31(8), 1050. 
67 C. S. Chern, C. K. Lee and C. C. Ho, Colloid Polym. Sci., 1999, 277(10), 979.

68 J. M. Vargas, L. M. Socolovsky, M. Knobel and D. Zanchet, Nanotechnology, 2005, 16(5), S285.

69 A. Vonarbourg, C. Passirani, P. Saulnier and J.-P. Benoit, Biomaterials, 2006, 27(24), 4356.

70 L. D. Galuppo, S. W. Kamau, B. Steitz, P. O. Hassa, M. Hilbe, L. Vaughan, S. Koch, A. Fink-Petri, M. Hofman, H. Hofman, M. O. Hottiger and B. Rechenberg, J. Nanosci. Nanotechnol., 2006, 6(9-10), 2841.

71 N. M. Schaeublin, L. K. Braydich-Stolle, E. I. Maurer, K. Park, R. I. MacCuspie, A. R. M. N. Afrooz, R. A. Vaia, N. B. Saleh and S. M. Hussain, Langmuir, 2012, 28(6), 3248.
72 P. M. Hinderliter, K. R. Minard, G. Orr, W. B. Chrisler, B. D. Thrall, J. G. Pounds and J. G. Teeguarden, Part. Fibre Toxicol., 2010, 7(1), 36.

73 S. D. Conner and S. L. Schmid, Nature, 2003, 422(6927), 37.

$74 \mathrm{~V}$. Stone, H. Johnston and M. J. D. Clift, IEEE Trans. NanoBiosci., 2007, 6(4), 331.

75 C. Brandenberger, C. Mühlfeld, Z. Ali, A.-G. Lenz, O. Schmid, W. J. Parak, P. Gehr and B. Rothen-Rutishauser, Small, 2010, 6(15), 1669.

76 A. Albanese and W. C. Chan, ACS Nano, 2011, 5(7), 5478.

77 M. Geiser, B. Rothen-Rutishauser, N. Kapp, S. Schürch, W. Kreyling, H. Schulz, M. Semmler, V. Im Hof, J. Heyder and P. Gehr, Environ. Health Perspect., 2005, 113(11), 1555. 